\title{
A Rare Case Report of 'Fetus in Fetu' in a One Year Eight Month Old Child
}

\author{
Manas Mukul Mandal ${ }^{\circledR}$, Rohit Shaw ${ }^{\circledR 1}$, Narendranath Mukhopadhyay ${ }^{\circledR 2}$, Sumon Kumar Saha ${ }^{\circledR 1}$ \\ ${ }^{1}$ Former Resident Doctor, Department of Radio Diagnosis, Burdwan Medical College \& Hospital, Burdwan, West Bengal, India, ${ }^{2}$ Professor, Department of General \\ Surgery, Burdwan Medical College \& Hospital, Burdwan, West Bengal, India.
}

\section{Abstract}

Fetus in fetu is a very unusual pathology in which a deformed underdeveloped fetus is found inside the body of another child. It is an uncommon abnormality and thought to be a result of abnormal embryogenesis in the case of diamniotic monochorionic pregnancy. Most commonly presents as a palpable mass in the abdomen. Imaging modalities can reveal the presence of bony elements within the mass cavity like vertebral bodies, long bones, and even underdeveloped organ systems. It should be differentiated from mature or well-organized teratoma \& other causes of infantile abdominal masses like Nephroblastoma, Neuroblastoma, Hydronephrosis \& malignant germ cell tumors in undescended testis. Surgery is the mainstay of treatment. To date around two hundred cases have been reported worldwide.

Keywords: Fetus in fetu, mass abdomen, abnormal embryogenesis, Nephroblastoma Neuroblastoma

Corresponding Author: Manas Mukul Mandal

E-mail: manas095@gmail.com

Received: 01 August 2020

Revised: 15 September 2020

Accepted: 24 September 2020

Published: 06 October 2020

\section{Introduction}

The term 'Fetus in fetu' means the presence of one twin in the body of the other. The first incidence was noted by George William Young in the year 1808. ${ }^{[1]}$ But the term was given by Johann Friedrich Meckel in the 18th century. He defined it as an 'encapsulated fetoid tumor' inside the body of another fetus. ${ }^{[2]}$

Two separate theories have been proposed to describe the development of this condition. One is abnormal embryogenesis in a diamniotic monochorionic pregnancy and another theory says it is a differentiated teratoma. ${ }^{[3]}$ In 1866 Dönitz proposed a theory that it is a case of symmetrical twins where the pathological twin has suffered the damage due to vascular compromise. It can be differentiated from teratoma by the presence of bony structures as it has crossed the initial stage of development. But differentiating it from other causes of infantile abdominal masses is necessary like Nephroblastoma, Neuroblastoma, Hydronephrosis \& malignant germ cell tumors in undescended testis. It can present as intraperitoneal, retroperitoneal, rarely-scrotum, and even cranial cavity mass. But usually found in the intra-abdominal retroperitoneal location. The mass cavity is covered by a thin membrane similar to an amniotic sac. But there is no placenta like structure which explains the reason for the lack of growth of the pathological fetus. They commonly have supernumerary limbs but may also contain visceral parts or whole organs, rarely a beating heart or intact brain. Pressure wielded by the host structures also results in the underdevelopment of the fetus ${ }^{[4]}$

It is a very rare condition found in about 1 in $5,00,000$ newborns. And till date around two hundred cases have been reported worldwide. ${ }^{[4]}$

\section{Case Presentation:}

A one-year eight-month-old child presented with an abdominal mass since birth in our surgery outpatient department of Burdwan Medical College and Hospital. The child had no specific complaint other than early satiety and infrequent vomiting. Antenatal history of the mother had no significant incident of radiation exposure or unmonitored drug intake that may cause such pathology. It was the firstborn child and the mother had no history of twin pregnancies in the past.

On clinical examination, a globular mass palpated in the abdomino-pelvic region with alternate soft and bony consistency, this aroused suspicion of 'fetus in fetu'. The child does not complain of any pain while palpating. The patient was admitted to the surgery ward for further evaluation and curative intervention as necessary. 


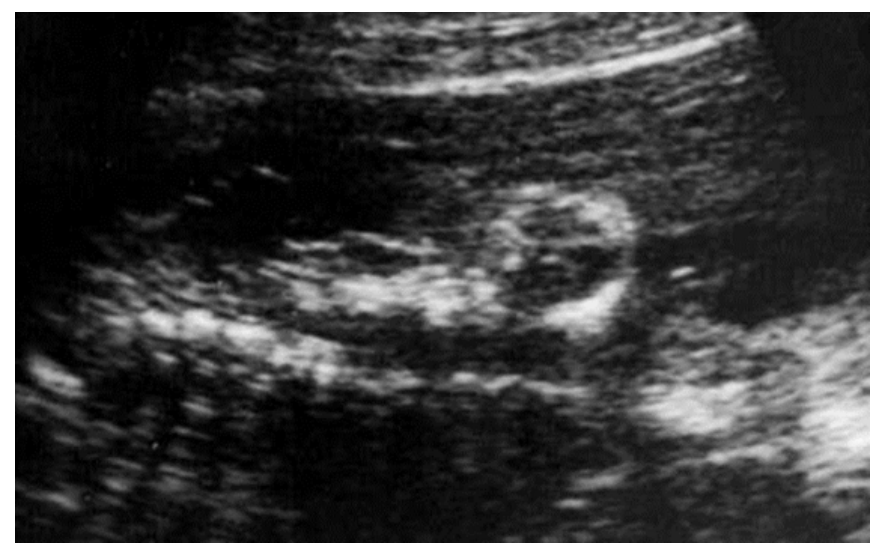

Figure 1: USG-A large complex mass in abdomino-pelvic region with cystic and solid calcified components.

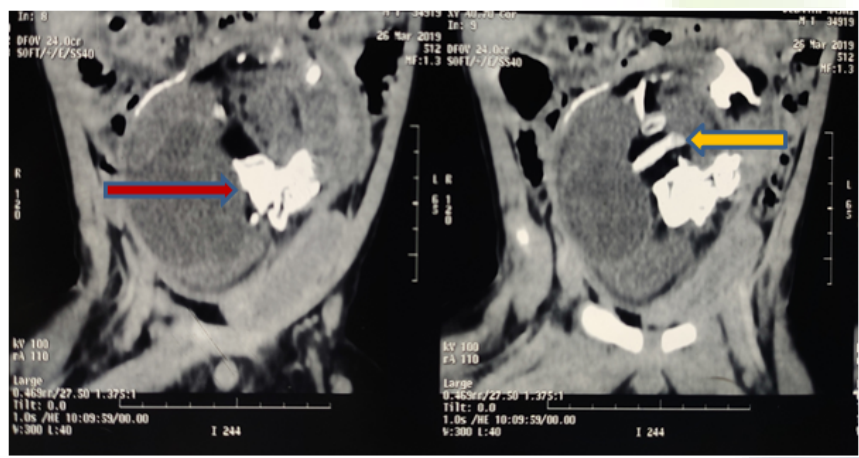

Figure 2: CT Scan- Presumed vertebral element (Red Arrow) and presumed limb bones (Yellow Arrow)

On ultrasonography, a large complex mass is seen in the abdomino-pelvic region with variable cystic and solid components and also the presence of calcified elements [Figure 1]. CT scan revealed abdomino-pelvic complex solid cystic SOL with incomplete peripheral calcification, an internal ring, nodular and linear pattern of calcification with a dependent layering of fluid and internal fat density. CT Scan also revealed the presence of presumed vertebral elements and limb bones within the mass cavity [Figure 2]. CT Scan with 3D Reconstruction in bone algorithm indicated the presence of multiple bony structures mimicking the vertebral bony column, specifically the cervical vertebra with foramen transversarium [Figure 3]. These imaging findings confirmed our initial diagnosis of 'fetus in fetu.

After adequate preoperative preparation, we performed an elective midline laparotomy with a vertical incision. On exploration of the abdomen a large retroperitoneal soft tissue lesion is found with gross adhesion to the mesentery and bladder. There was no adherence to the surrounding gut.

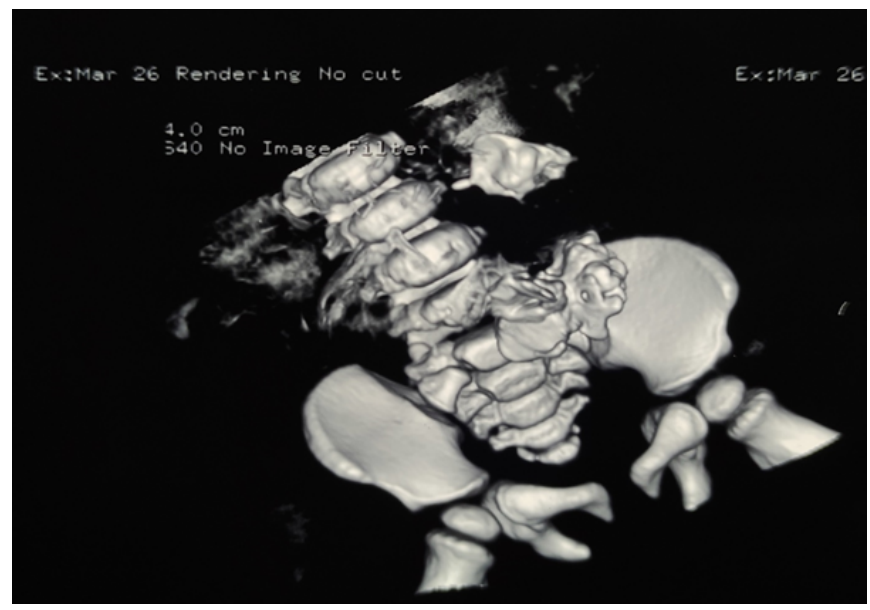

Figure 3: 3DReconctructed CT Image- Rudimentary cervical vertebral elements with foramen transversarium (Red Arrow).

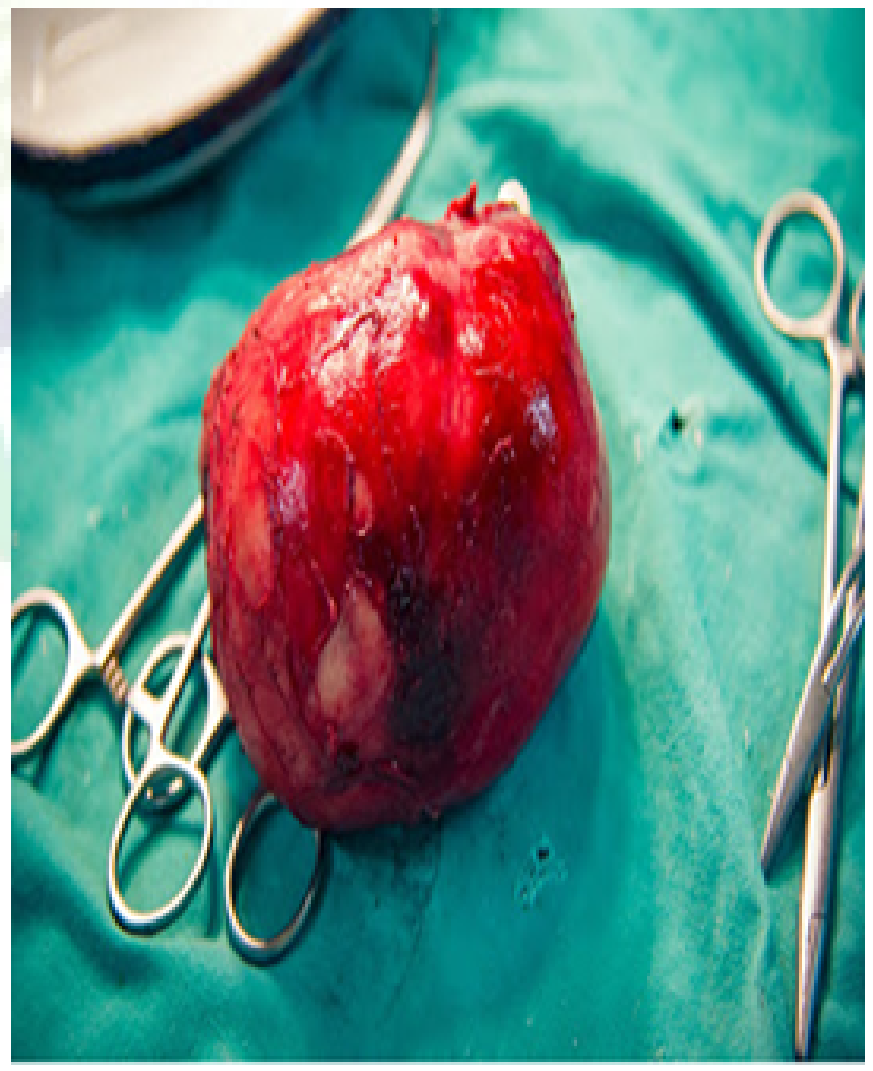

Figure 4: Showing resected surgicalspecimen with Identifiable hair (GREEN ARROW), Rudimentary limb bud (SKYBLUEARROW). 
A membrane or capsule-like structure was covering the lesion [Figure 4] which on removal exposed tissue having calvaria with hair, hypoplastic limbs, and a small trunk [Figure 5]. The membrane was retrospectively diagnosed as a chorioamniotic membrane. The mass was excised completely with little difficulty. The specimen was so characteristic, no HPE was carried out. The specimen was sent to the department museum for conservation. The child was closely monitored in the postoperative period and discharged after 10 days of observation. The patient also had no further complaint in the follow-up period and recovered well from the surgery.

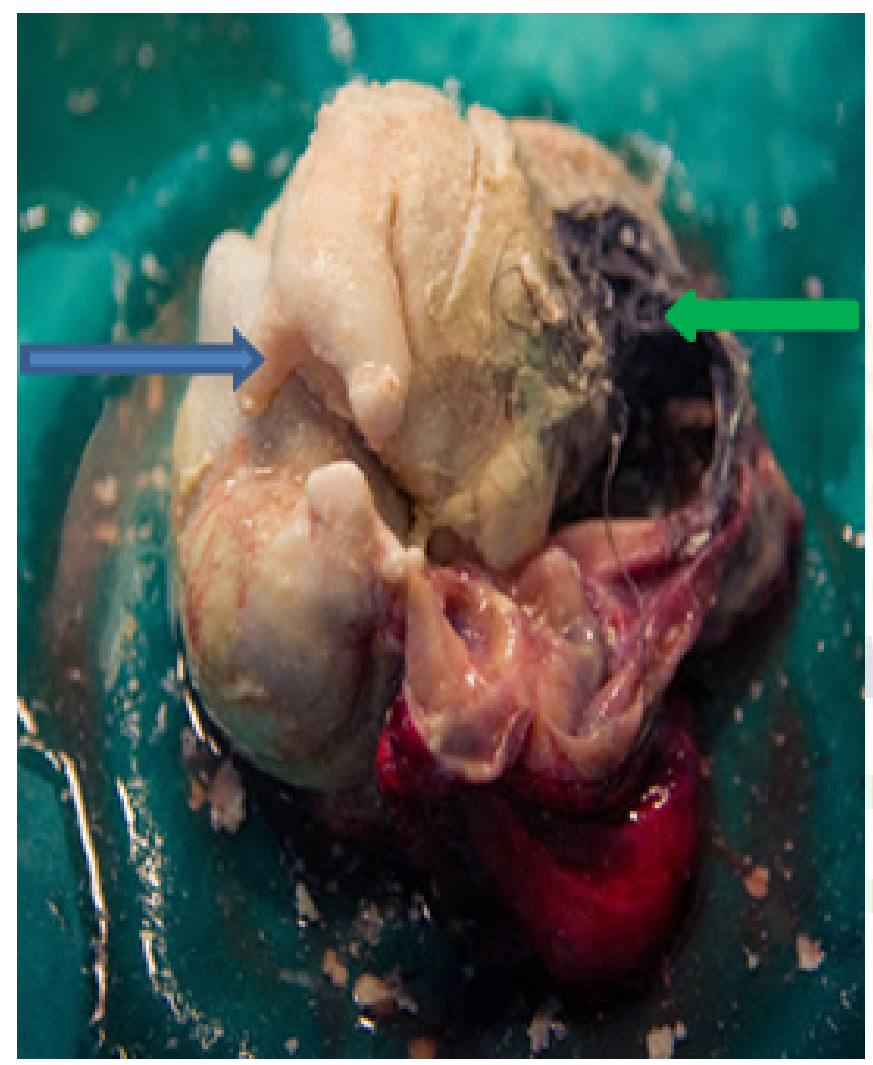

Figure 5: Showing resected surgicalspecimen with Identifiable hair (GREEN ARROW), Rudimentary limb bud (SKYBLUEARROW).

\section{Discussion:}

In our case, we found the presence of a single pathological fetus within the abdomen of a normally growing child. Though at instances multiple fetuses altogether can also be present, as reported by Rebecca et al. ${ }^{[2]}$ According to Tada et al, the most common location of fetus in fetu is retroperitoneum. ${ }^{[5]}$ Intra- operatively we encountered a similar finding of a complex mass retroperitoneally, adherent to the bladder. In his study, Rupert Allan Willis, ${ }^{[6]}$ suggested that the presence of axial skeleton, limb bones supports the diagnosis of 'fetus in fetu' which corresponds with the finding of our specimen. And such presence of vertebral elements, limb bones, and craniocaudal differentiation [Figure 5] in our case also clearly differentiates it from the teratoma. The vertebral column was detected in our case as a radio-opaque relatively calcified structure. [Figure 2 and Figure 3].

\section{Conclusion}

'Fetus in fetu' is an unusual pathology and usually found at very young age. Most common presentation is a mass in the abdomen. But before operating and concluding the diagnosis we must rule out other pathologies with similar presentation.

\section{References}

1. Young GW. Case of aFœtusFound in the Abdomen of a Boy. Med Chir Trans . 1809;1:236-264.

2. Gerber RE, Kamaya A, Miller SS, Cronin DM, Dwyer B, Chueh J, et al. Fetus In Fetu: 11 Fetoid Forms in a Single Fetus. J Med Ultrasound. 2008;27(9):1381-1387. Available from: https: //dx.doi.org/10.7863/jum.2008.27.9.1381.

3. Harigovind D, SP HB, Nair SV, Sangram N. Fetus in fetu - a rare developmental anomaly. Radiol Case Reports. 2019;14(3):333336. Available from: https://dx.doi.org/10.1016/j.radcr.2018.11. 020.

4. Sharma A, Goyal A, Sharma S. Fetus in fetu: A rare case report. J Res Med Sci. 2012;17(5):491-491.

5. Tada S, Yasukochi H, Ohtaki C, Fukuta A, Takanashi R. Fetus in fetu. Br J Radiol. 1974;47(554):146-148. Available from: https://dx.doi.org/10.1259/0007-1285-47-554-146.

6. Willis RA. The borderland of embryology and pathology. London: Butterworths Washington DC; 1962.

Copyright: (C) the author(s), 2020. It is an open-access article distributed under the terms of the Creative Commons Attribution License (CC BY 4.0), which permits authors to retain ownership of the copyright for their content, and allow anyone to download, reuse, reprint, modify, distribute and/or copy the content as long as the original authors and source are cited.

How to cite this article: Mandal MM, Shaw R, Mukhopadhyay N, Saha SK. A Rare Case Report of 'Fetus in Fetu' in a One Year Eight Month Old Child. Asian J. Med. Res. 2020;9(3):1-3.

DOI: dx.doi.org/10.47009/ajmr.2020.9.3.SG1

Source of Support: Nil, Conflict of Interest: None declared. 